\title{
Algumas considerações sobre a obra Oboé solo 1 a 4 de Heitor Alimonda
}

\author{
Lucius Mota \\ Fúlvio Ferrari
}

Resumo: Neste artigo discute-se a única obra conhecida para oboé solo de Heitor Alimonda. Com o objetivo de se contextualizar o autor e sua obra, realizou-se uma revisão bibliográfica e entrevistas com dois intérpretes. Observa-se que a obra tem alto valor artístico e que merece maior divulgação. Através da análise da obra se entende que se trata de uma suíte em quatro breves movimentos. Algumas sugestões de interpretação também são propostas.

Abstract: In this text we discuss the only known piece for solo oboe by Heitor Alimonda. A bibliographic review and interviews with two interprets have been made in other to contextualize the author. Through an analyses of the piece we thing that the work is a Suite in four short movements. Some suggestions about the interpretation of the piece were made.

Heitor Alimonda é conhecido como um importante pedagogo do piano (Abreu, 1992, p.264), instrumentista de alto nível e camerista com importante atuação profissional. Face menos conhecida de sua carreira é a de compositor. Neste artigo será abordada sua única obra escrita para oboé solo intitulada Oboé Solo 1 a 4, composta em 1974 e dedicada ao oboísta italiano Paolo Nardi. Tendo em vista a escassa literatura sobre Alimonda, também se fará uma revisão bibliográfica bem como uma breve introdução à música para oboé solo com o propósito de contextualizar a obra em questão dentro do repertório do instrumento.

O catálogo do autor (Brasil, 1977), já bastante desatualizado, mostra uma preponderância de obras de música de câmara, para canto e piano e um pequeno número de obras para piano, sendo que apenas 12 
são citadas (Gandelman, 1997, p.39). A obra Oboé solo 1 a 4 consta entre as obras do compositor que foram gravadas'. Outras duas gravações são: 5 peças breves para três instrumentos melódicos registradas pelo trio Morozowicz, Botelho, Devos, (FUNARTE, 1981b), e o Trio para violino, violoncelo e piano, esta última ganhadora de um concurso promovido pela Rádio MEC e gravada pelo Trio da Rádio MEC em 1960 (FUNARTE, 1981).

Nos comentários do encarte da gravação do Trio, Alimonda fala brevemente sobre seu período de estudos na Inglaterra:

Havia estudado alguma composição e já escrito tantas peças para piano (pedagogia principalmente), canto e pouco para outros instrumentos, quando cheguei a Londres para um período de pouco mais de um ano, estudando na Royal Academy of Music, em Londres - o foco principal em pedagogia do piano. As aulas de harmonia e história da música, ambas bastante apoiadas em análise, desenvolveram muito minha visão analítica musical, [e] conceitos formais" (Alimonda, in FUNARTE, 1981, p.5).

Alimonda também teve aulas com Hans-Joachim Koellreuter (1915-2005):

Fui aluno de Koellreuter na época áurea do dodecafonismo no Brasil, quando se tentou reformular e internacionalizar ideias e estéticas musicais. Estes estudos não duraram tanto tempo para desenvolver uma técnica atonalista, mas foram suficientes para, pelo menos, permitir uma certa liberdade tonal presente nas minhas composições (Alimonda, idem).

I A gravação desta obra esta disponível no site de Ricardo Rodrigues: <http://www.online-oboe.de/Aa_Oboe_Solo.htm>, acesso 25/02/2016 
Além das aulas com Koellreuter e do período de estudos em Londres, Alimonda também foi aluno de Vittorio Giannini (1903-66) nos Estados Unidos (Correia, 1977). Observa-se que a sua formação como compositor não foi o foco principal de seus estudos, mas ocorreu paralelamente à sua formação pianística.

Ainda sobre sua formação e também sobre suas escolhas estéticas, Alimonda escreveu um artigo dedicado à obra de César Guerra-Peixe (1914-1993). Nesse texto, Alimonda se reporta às discussões que manteve com Guerra-Peixe nos anos de 1940 a 1950, provavelmente um período em que ambos foram alunos de Koellreuter:

Para que entenda essa minha colocação, é preciso que se torne ao início dos anos quarenta, início dos anos cinquenta quando minha comunicação com o Guerra era intensa e constante. Do meu lado predominava em nossas conversas minha aversão à "música feia" que o Guerra dodecafônico escreveu bastante (Alimonda, apud Faria, Barros, Serrão, 2007, p.107).

O texto, publicado após a morte de Alimonda, foi escrito provavelmente entre 1993 e 2000 . A discussão sobre "música feia", que seria para o autor a música dodecafônica, é ainda mais interessante quando se observa que na obra aqui discutida, a qual se não chega a ser dodecafônica, é bastante cromática. A obra para oboé solo demonstra a "liberdade tonal" que o próprio Alimonda afirmava haver em suas obras e indica que o compositor não se limitava à tonalidade tradicional, ainda que não tenha adotado a técnica dodecafônica.

Ainda em torno da discussão sobre "o feio e o bonito" em música, no mesmo artigo Alimonda aborda a música dos três volumes iniciais do Mikrokosmos de Bela Bartok (1881-1945). Para Alimonda, e também para Guerra-Peixe, esses volumes são "preferivelmente métodos de composição e não produção sonora de música dentro de um conceito não teórico" (Alimonda, in Faria, Barros, Serrão, 2007, p.107). 
Para o compositor, nesses volumes Bartok apresentou "processos composicionais muito elementares, até certo ponto, hermética e formalmente". Em seguida, Alimonda, citando Gerd Kaemper, afirma que falta nesta obra, o Mikrokosmos, "beleza e emoção" (Alimonda, in Faria, Barros, Serrão, 2007, p.107). Ora, Alimonda parece não condenar de antemão o atonalismo, ou o cromatismo que ele mesmo utiliza em sua música, a questão seria a falta de "beleza e emoção" que observa tanto na "feia" música dodecafônica, quanto no "hermético" Bartók.

Dando prosseguimento ao texto, far-se-á uma digressão sobre a música para oboé solo, para em seguida abordar a peça em detalhe. Espera-se que a análise do Oboé solo 1 a 4 demonstre como Alimonda entendia o que deveria ser o "bonito" em música: uma obra que busca a "emoção", a comunicação com os ouvintes através do intérprete tendo como técnica a liberdade tonal.

\section{Algumas considerações sobre a música para oboé solo}

O repertório do oboé é relativamente pequeno quando comparado a outros instrumentos de madeira. As explicações mais citadas para tal fato são as limitações do instrumento. Por exemplo, sua pequena extensão e pouca agilidade. Essas limitações são um desafio inicial ao compositor e, ao optar por escrever algo para oboé solo, o desafio se torna ainda maior.

Diversas obras para oboé solo do século XVIII fazem parte do repertório do instrumento. Todavia, como é típico da música para oboé, há poucas obras escritas para o instrumento no século XIX. No século $X X$, em parte graças à atuação de oboístas que tanto encomendaram como estrearam obras a eles dedicadas, surgiu grande quantidade de obras originais para o oboé (Burguess, 2004:196). A título de exemplo e para demonstrar a diversidade de estilos do repertório atual, cita-se a Six Metamorphoses after Ovid, de Benjamin Britten (1913-76), a 
Sequenza VII, de Luciano Berio (1925-2003), ou a Sonatina de Ernst Krenek (1900-91). No primeiro dos exemplos citados, Britten utiliza uma escrita tradicional do instrumento, num idioma modal e tonal, Berio explora a técnica expandida e Krenek, apesar de escrever num idioma atonal, utiliza também a técnica tradicional.

No Brasil, curiosamente, há uma preponderância de obras breves, num único movimento. Algumas características são marcantes nas obras brasileiras para oboé solo. Algumas exploram o caráter lírico do instrumento, tais como o Improviso, de Osvaldo Lacerda (1927-2011) e o Pequeno Trecho de Discurso Musical, de Aylton Escobar (1943); outras exploram a virtuosidade, como a Fantasia Sul América, de Cláudio Santoro (1919-1989), e Metáfora, de Emilio Terraza (1929-2011). Há ainda as obras que exploram a técnica expandida, como, por exemplo, a Mutationen $X$, de Cláudio Santoro. Dentre as obras brasileiras em vários movimentos, além de Oboé Solo 1 a 4, destaque-se o Ponteio e Dança de José Alberto Kaplan (1935-2009); os Três movimentos para oboé solo, de Estércio Marquez Cunha (1941); as Três Danças, de Jaime Zenamon (1953); os 4 esboços, de Mário Ficarelli (1935), e a Partita, de Ernst Widmer (1927-1990).

\section{Alguma literatura sobre a música para oboé no Brasil}

Apesar de haver um número expressivo de obras brasileiras dedicadas ao oboé, a literatura acadêmica sobre a música brasileira para instrumento não é vasta. O Concertino para oboé e cordas, de Brenno Blauth (1931-1993) foi objeto de dissertação de Mosineide Schulz Ribeiro Pestana de Souza (Souza, 2010). Também há uma dissertação sobre a Sonatina para oboé e piano de José Siqueira (Gonçalves, 1999). A Sonatina (1943) para oboé e piano e a Fantasia Sul América, ambas de Cláudio Santoro (1919-1989), foram analisadas em trabalhos dedicados ao autor (Oliveira, 2010; Mendes, 2009). Paulo Costa Lima examinou em 
detalhe o primeiro movimento da Partita para oboé solo de Ernst Widmer (Lima, 1999:211).

\section{A origem da obra}

Como mencionado anteriormente, o Oboé solo 1 a 4 foi dedicada ao oboísta italiano Paolo Nardi, músico que veio ainda criança para o Brasil. Nardi estudou primeiramente clarineta, mas o gosto pessoal pela música barroca o fez optar pelo oboé, cujo repertório barroco é bastante numeroso. Paolo Nardi fez parte do Sexteto de Rio e de outras formações camerísticas juntamente com Heitor Alimonda (Nardi, 2013:comunicação eletrônica). Segundo Paolo Nardi, a obra foi um presente de Alimonda:

Ele [Alimonda] me deu de presente em ocasião de uma viagem sua à Europa. [A] toquei em publico num recital de obras contemporâneas, para oboé solo organizado pelo compositor florentino D. Lombardi, no Castelo da cidade de Prato, por volta de '76. (Nardi, 2013: comunicação eletrônica).

Uma vez que a obra foi gravada por Ricardo Rodrigues, fez-se contato com o intérprete com a esperança de que o compositor houvesse feito algum comentário sobre a escolha do curioso título da peça. Rodrigues afirma que os comentários do compositor foram breves. Quanto ao título, ele teria dito que "se tratava de uma brincadeira, ou um jogo", o título teria dois significados: "quatro peças que deveriam ser tocadas, da primeira à quarta [,] e o final de um jogo, em que o perdedor é valorizado, pois o resultado é dado como Oboé Solo 1 a 4 e não 4 a 1 " (Rodrigues, 2013). De imediato se infere que o compositor criou um ciclo, pois as obras devem ser tocadas "da primeira à quarta". Também se poderia pensar que a peça tem o caráter de divertimento, tão comum 
à música para sopros. Entretanto o estilo da obra é mais sério. Seria o título um jogo, um divertimento do próprio compositor?

\section{O oboé solo de Alimonda}

Se a obra forma um ciclo, como se mencionou acima, primeiramente se poderia pensar que se trata de uma suíte com movimentos contrastantes, ou num ciclo de sonata em miniatura ${ }^{2}$. No caso de Oboé Solo 1 a 4, a estrutura da obra sugere que se trata de uma suíte, pois como define Stein, os movimentos não possuem integração suficiente entre os movimentos para formar uma sonata (Stein, 1979, p.160). O estilo de cada movimento poderia ser definido da seguinte forma: um prelúdio, uma ária, um scherzo e finalmente uma dança rápida (um chorinho?).

O primeiro movimento possui escrita livre, quase improvisatória, o que sugere o estilo de prelúdio. Quanto ao aspecto harmônico e melódico, verifica-se que no início da peça as sete primeiras notas insinuam a escala de Dó menor melódica. Contudo, logo que se atinge a sensível e espera-se uma resolução que poderia definir firmemente a tonalidade, o compositor substitui a tônica esperada, Dó natural, por um Dó sustenido, seguido por Ré sustenido, completando assim uma escala de tons inteiros (Figura 1). É a escala de tons inteiros, em suas duas transposições (portanto o total cromático), que formam o material melódico deste movimento. Este procedimento, no qual Alimonda parece trilhar um caminho, para logo em seguida mudar de rumo, será frequente no decorrer da obra.

\footnotetext{
2 Um exemplo de ciclo sonata em miniatura é a Sonatina para oboé solo de Ernst Krenek, que também tem quatro movimentos, a saber: Allegro, Adagio, Scherzo, e Tema e Variações, com uma duração de cerca de cinco minutos, a mesma de Oboé Solo 1 a 4.
} 
Figura 1: Início do primeiro movimento.

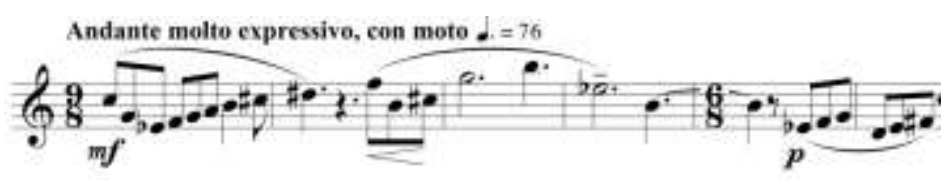

No compasso 20, há uma mudança de andamento, poco più movido, e de fórmula de compasso $6 / 8$ para $3 / 4$. Nesta nova seção, o andamento é mais flexível, sugerido por expressões tais como poco apressando, calmando. Para finalizar o movimento, há um breve retorno ao andamento inicial nos últimos compassos. O clímax do movimento, de apenas 35 compassos, é atingido no compasso 29 .

Se o começo deste prelúdio se inicia com um arpejo de Dó menor, o compositor usa ao final um arpejo de Si maior com sétima (enarmonizando-se o Mib em Ré\#) conferindo, assim, um caráter suspensivo e muito expressivo ao fim do movimento (Figura 2).

Figura 2: Final do primeiro movimento.

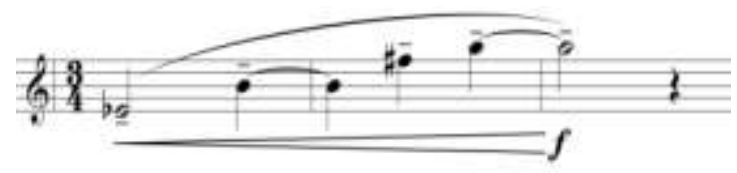

O conciso segundo movimento, 21 compassos, com indicação de Lento, tem o caráter lírico de uma Aria. No princípio deste movimento, o compositor explora intervalos de segundas menores e terças, em seguida, intervalos de terça menor, formando acordes diminutos (Figura 3). A escrita explora a região grave e mais sonora do instrumento. $O$ clímax ocorre no compasso 10, quase no centro do movimento. Como no prelúdio, também é explorada uma escrita que sugere um improviso. Ao final desta Aria, o compositor utiliza novamente os acordes diminutos e os intervalos de segunda menor e terças. O movimento é concluído 
com as mesmas três notas do início, em ordem diferente (Figura 4). Esse movimento também pode ser dividido em duas seções: dos compassos 1 ao 9 e de 10 ao 21. A primeira seção explora contrastes dinâmicos dentro de um pequeno espaço intervalar. Na segunda seção, frases com intervalos mais amplos aprofundam a expressividade do movimento.

Figura 3: Início do segundo movimento.

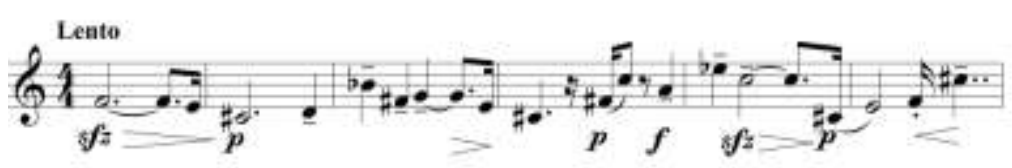

Figura 4: Final do segundo movimento.

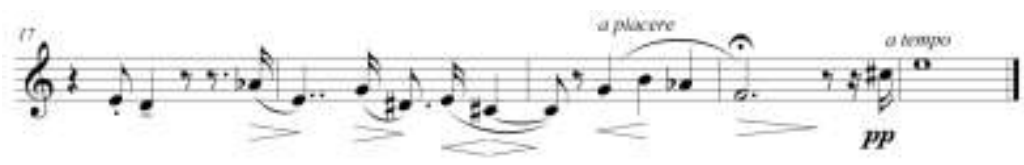

O terceiro movimento, Allegretto espressivo, 61 compassos, apresenta logo no início a síncopa, ritmo tão valorizado na música brasileira de estilo nacionalista do século $X X$ e que confere ao movimento um certo caráter de Scherzo, sem no entanto fazer uma referência direta ao nacionalismo (Figura 5). Alimonda explora o trítono e o semitom evitando centros tonais claros, como o fez nos movimentos anteriores. Ocorre no compasso 42 uma seção em tercinas que conduz ao clímax (Figura 6). As tercinas desta seção estão baseadas em acordes de nonas, o que se observará também no último movimento. Neste movimento, como no seguinte, há uma aproximação mais clara à forma ternária, pois o compositor retoma na seção final do movimento o motivo melódico-intervalar inicial, mas com outro ritmo (Figura 7). 0 
autor utiliza também elementos expressivos e agógicos, tais como sostenuto e con tristezza, dando certa liberdade ao intérprete.

Figura 5: Início do terceiro movimento em síncopas.

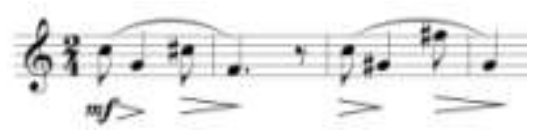

Figura 6: Clímax do terceiro movimento.

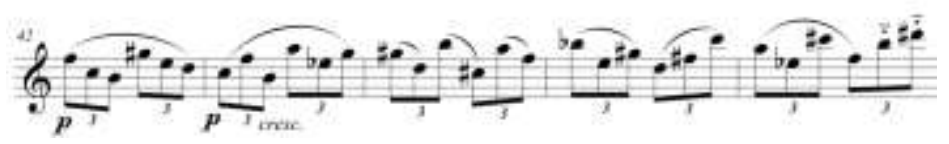

Figura 7: Final do terceiro movimento, retomada do motivo inicial.

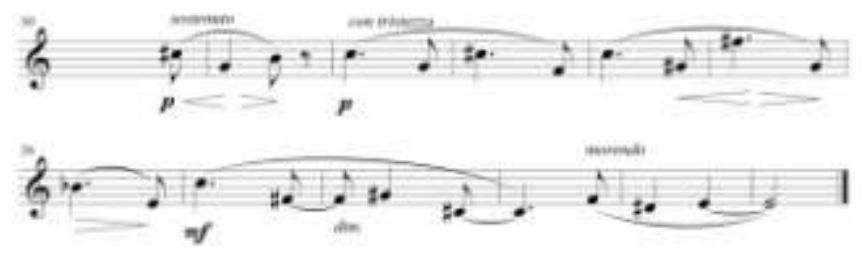

O último movimento tem a indicação Presto possibile. Quanto ao estilo, esse movimento pode ser considerado como uma dança rápida. $\mathrm{O}$ andamento rápido e o ritmo anacrúsico inicial lembram uma dança barroca bastante estilizada, ou poderia o caráter virtuosístico insinuar um chorinho?

A melodia do início deste movimento também evita centros tonais claros. No entanto, é possível organizar as frequências do primeiro motivo em acordes de terças superpostas. Observa-se que as primeiras sete notas podem ser dispostas como um acorde de Dó sustenido menor com $11^{\text {a }}\left(\mathrm{CH}^{11}\right)$. As notas do segundo compasso também podem ser organizadas num acorde de Mi maior com $11^{\text {a }}$ aumentada (Figura 8). 
Desta forma, o compositor transforma em linha melódica uma organização harmônica previamente estabelecida.

Figura 8: Início do quarto movimento, melodia das semicolcheias organizadas em acordes.

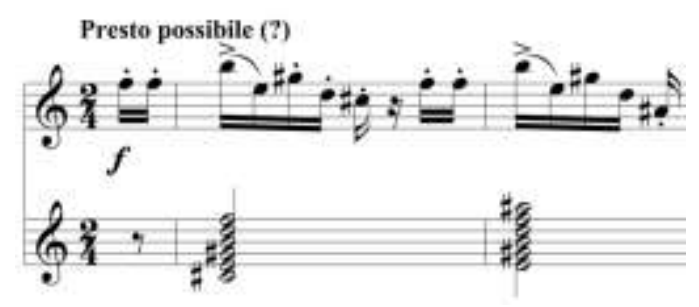

Assim como se observou nos movimentos anteriores, Alimonda divide claramente as seções deste último tempo através do rítmo. $\mathrm{Na}$ primeira seção, o compositor utiliza semicolcheias (Figura 8). Em seguida, uma seção em tercinas, com a indicação indeciso, também construída com arpejos de acordes com $11^{\text {a }}$ (Figura 9).

Figura 9: Seção central em tercinas e clímax do quarto movimento, c.24.

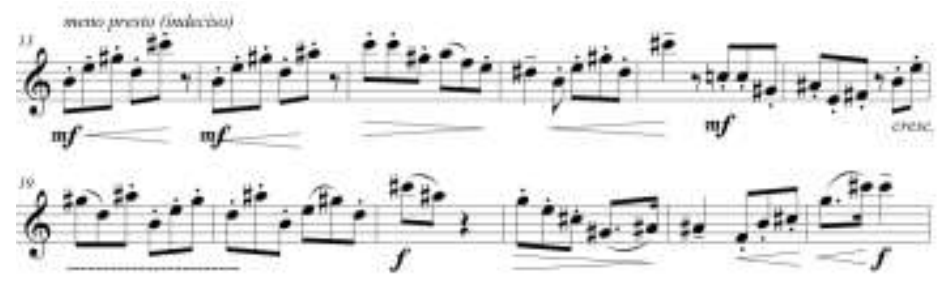

Uma nova seção tem início no compasso 25, com a predominância de colcheias. Este procedimento cria um ralentando escrito que é seguido pela última seção que retoma o ritmo com semicolcheias, compasso 37. Percebe-se que a notação utiliza intervalos de quartas, porém o intervalo inicial, uma quarta diminuta, La bemol-Mi natural, seguido por um Dó\#, formam enarmonicamente um arpejo de Dó sustenido menor. (Figura 10). Esse retorno das semicolcheias, aliado ao uso do mesmo material harmônico, cria o design da forma ternária. 
Figura 10: Final do quarto movimento, recapitulação em semicolcheias.

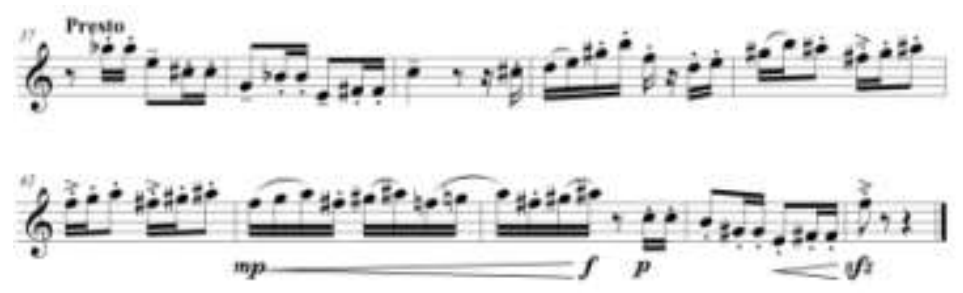

Uma vez que na organização interna dos movimentos a divisão das seções se dá pela utilização de ritmos, ou de figuras rítmicas diferentes, essa organização substitui a repetição literal de temas ou motivos melódicos, a revelar a fina técnica do compositor.

\section{Considerações finais}

Apesar das qualidades inerentes à Oboé solo 1 a 4, a obra ainda não encontrou espaço no repertório do oboé. Sempre se caberá a ressalva de que a obra encontra-se em manuscrito ${ }^{3}$ e de difícil acesso. A cópia do manuscrito que serviu de base a uma edição prática da obra, realizada para a elaboração desse artigo, foi fornecida pelo próprio compositor há muitos anos. Espera-se que esse texto sirva de incentivo para que a obra seja mais divulgada.

O professor de piano Heitor Alimonda dizia a seus alunos que "a obediência e o respeito ao texto eram fundamentais [e] os critérios interpretativos deviam ser tomados dos elementos da estrutura da partitura" (Carrara, 2010, p.82). Se o professor-intérprete Alimonda recomenda que se siga a partitura fielmente, o compositor Alimonda é

3 Os manuscritos do autor foram doados a Biblioteca Alberto Nepomuceno da UFRJ.

http:// www.musica.ufrj.br/index.php?option=com_content\&view=article\&id=14 76: ban-reabre-mais-moderna\&catid $=55$ :destaques\&ltemid=149 . Acesso em $31 / 12 / 2013$. 
bastante detalhista na notação de Oboé Solo 1 a 4. Embora o intérprete deva seguir de perto o autor, ainda assim a obra deixa grande margem de expressão e escolhas ao oboísta, sendo que uma análise da obra pode contribuir para uma interpretação bem sucedida.

Apesar da análise demonstrar elementos harmônicos tonais, o compositor trabalha de forma a evitar relações funcionais óbvias na textura harmônica, o que leva o ouvinte a perceber a obra como tendo um caráter atonal. Sob o ponto de vista da escrita idiomática, a obra é primorosamente escrita para o oboé. A tessitura ${ }^{4}$ explora a região mais confortável do instrumento. Do ponto de vista técnico, o grau de dificuldade é relativamente alto e não é destinada para iniciantes. Afinal, Alimonda conhecia as qualidades do oboísta para quem escreveu a obra.

Dentro do contexto música brasileira para oboé solo, e mesmo do repertório internacional do instrumento como um todo, o Oboé Solo 1 a 4 se apresenta como um desafio artístico e técnico ao instrumentista que reclama a atenção dos oboístas. A escrita da obra demonstra que Heitor Alimonda, além de grande professor, pianista e camerísta, era compositor de refinada técnica composicional.

\section{Referências:}

ABREU, Maria. GUEDES, Zuleika Rosa. O piano na música brasileira: seus autores até 1950. Porto Alegre: Movimento, 1992.

ALIMONDA, Heitor. Oboé Solo 1 a 4 para oboé solo. Manuscrito. Rio de Janeiro, 1974.

5 peças breves para 3 instrumentos melódicos. Manuscrito. Rio de Janeiro, 1974-1979.

Variações em torno de um pedido de Guerra-Peixe. In: FARIA, Antonio Guerreito; BARROS, Luitgarde Oliveira Cavalcanti; SERRÃO, Ruth.: Guerra-Peixe: Músico Brasileiro. Rio de Janeiro. Lumiar Editora, 2007.

4 Tessitura do $1^{\circ}$ movimento: Dó\#3 ao Mi5; $2^{\circ}$ movimento: Dó\#3 a Dó\#5; $3^{\circ}$ movimento: Dó\#3 a Re\#5; $4^{\circ}$ movimento: Dó3 a Dó\#5. 
BRASIL. Catálogo de obras de Heitor Alimonda, 1977.

BURGESS, Geofrey. HAYNES, Bruce. The oboe. New Haven, USA. Yale University Press, 2004).

CARRARA, André. Deliberação expressiva e toque pianístico. Porto Alegre, 2010. 140f. Tese. UFRGS.

CORREIA, Sérgio Nepomuceno Alvim. Alimonda, Heitor. In: MARCONDES, Marcos Antonio. Enciclopédia Brasileira de Música: erudita, folclórica, popular. São Paulo: Art Editora Ltda, 1977. Vol 1, p. 14.

FUNARTE - BOCCHINO, Alceu. ZLATOPOLVSKY, Anselmo. GROSSO, Iberê. GuerraPeixe e Heitor Alimonda: trio da Rádio MEC. Estéreo. CD. ATR 32069. FUNARTE, 1981.

FUNARTE - MOROZOWICZ, Norton; BOTELHO, José; DEVOS, Noel. Música de Câmara do Brasil. Estéreo. Promemus. FUNARTE, 1981 b.

GONÇALVES, José Francisco. Uma abordagem da Sonatina para oboé e piano de José de Lima Siqueira à luz do sistema tri-modal brasileiro de sua autoria. Rio de Janeiro, 1999. Dissertação. UFRJ.

GANDELMAN, Salomea. 36 Compositores Brasileiros: obras para piano (1950/1988). Rio de Janeiro: FUNARTE, 1997.

LIMA, Paulo Costa. Ernst Widmer e o ensino da composição musical na Bahia. Salvador: COPENE Cultura e Arte Especial, 1999.

MENDES, Sérgio Nogueira. O percurso estilístico de Cláudio Santoro: roteiros divergentes e conjunção final. Campinas, 2009. 295f. Tese. UNICAMP.

NARDI, Paolo. Entrevista por email, concedida em 24/06/2013. Lúcius Mota, entrevistador.

RODRIGUES, Ricardo. Entrevista por email, concedida em 10-14/01/2013. Lúcius Mota, entrevistador.

OLIVEIRA, Reinaldo Marques. A conclusão cromática em obras de Arnold Schoenberg e Cláudio Santoro. São Paulo, 2010. $213 \mathrm{f}$. Tese. USP.

PERSICHETTI, Vincent. Armonia del siglo XX. Madrid: Real Musical, 1985.

RODRIGUES, Ricardo. SENISE, Luiz. O oboé na música brasileira. Estéreo. LP. MMB 87.054 1987. FUNARTE, 1987.

SOUZA, Mosineide Schulz Ribeiro Pestana. Concertino para oboé e orquestra de cordas T.17 de Breno Blauth: revisão, edição e redução da parte orquestral para piano. Rio de Janeiro, 2010. 268f. Dissertação, UNIRIO.

STEIN, Leon. Structure and style: the study and analysis of musical forms. Kindle edition. Alfred Music, 1979. 